\title{
ANALYSIS OF PULSED OPERATING MODE OF LINEAR INDUCTION DRIVE OF GRAIN CLEANING MACHINE
}

\author{
A. Linenko \\ Bashkir State Agrarian University \\ Ufa, Russian Federation \\ Linenko-bsau@yandex.ru \\ M. Tuktarov \\ Bashkir State Agrarian University \\ Ufa, Russian Federation \\ Marat.TukZar@yandex.ru
}

\author{
R. Aipov \\ Bashkir State Agrarian University \\ Ufa, Russian Federation \\ Rsaipov@mail.ru \\ V. Baynazarov \\ Bashkir State Agrarian University \\ Ufa, Russian Federation \\ Baynazv@mail.ru
}

\begin{abstract}
The authors of the paper present the results of theoretical research of the pulsed operating mode of linear electric sieve mill of grain cleaning machine MVR-2 (SU - 0.1). It is shown that when using a linear electric drive in the grain cleaning machine in a pulsed mode, the productivity is increased by $20 \%$.
\end{abstract}

Keywords - linear induction motor, linear drive, microprocessor control, pulse mode, parameters, fluctuations, efficiency.

\section{INTRODUCTION}

In many studies, much attention is paid to improving the design of grain-cleaning machine drives to enhance the efficiency of the grain separation process. In one of the studies, a grain cleaning machine is described, in which a flat linear induction motor is used [10].

Due to the possibility of a flat linear induction motor to create two electromagnetic forces that are mutually perpendicular to each other, there is oscillation of the seave boot along the composite path in the grain cleaning machine. The sieve mill oscillates along a complex trajectory. Such movement allows one to increase the ability of the grain material to orient to the sieve holes, which positively affects the efficiency of its separation [6]. A flat linear induction motor consists of an inductor and a secondary element, which in turn consists of an aluminum and steel sheet (Fig.1).

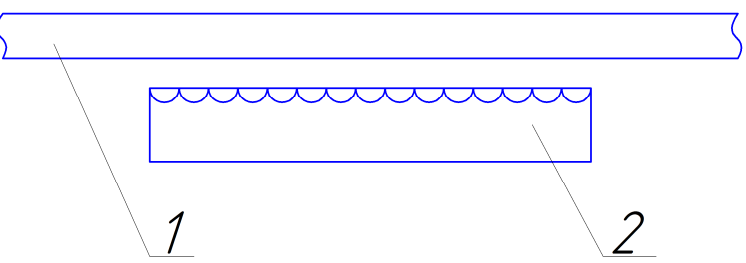

Fig. 1. - Flat linear induction motor: 1 - second element; 2 - inductor.
The main advantages of flat linear induction motor when using it in grain cleaning installations are the possibility of abandoning mechanical transmissions and the ability to create complex oscillatory movements, which became the cause of close attention of the developers of grain cleaning machines to this type of engine [1].

The grain cleaning machine based on a flat linear induction motor operates as follows. The control unit connects the inductor of the linear inductor motor to the power source; the inductor creates a traveling magnetic field. The interaction of the traveling magnetic field of the inductor with the rotor leads to the appearance of the following electromagnetic forces: $F_{x}$ is the longitudinal force directed along the traveling magnetic field of the inductor and $F_{y}$ is the attractive force perpendicular to longitudinal force $F_{x}$. Under the action of these forces, the rotor and, consequently, a sieve mill are set in motion $[8,10]$. The elastic elements simultaneously deform in the direction of forces $F_{x}$ and $F_{y}$ (Fig. 2).

At some point in time, the control unit de-energizes the inductor of the linear induction motor and its running magnetic field disappears. Under the action of the potential energy accumulated in the elastic elements as a result of their deformation, the working body returns to its original state. Then the described process is repeated. At the same time, the working organ performs a complex oscillatory motion [6]. 


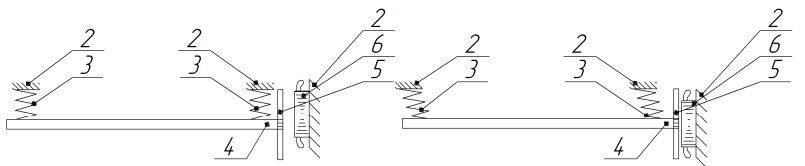

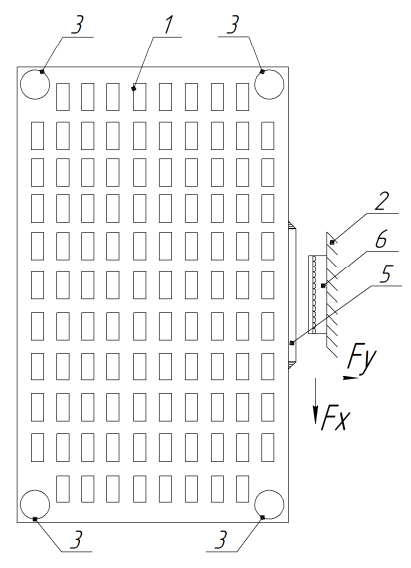

a

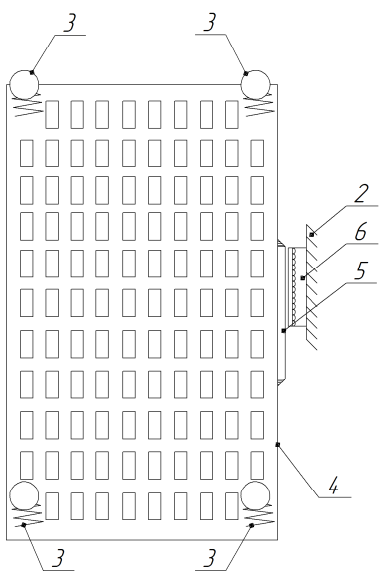

b

Fig. 2. - The linear electric drive of a sieve mill: 1 - separating cell; 2 - base; 3 - elastic element; 4 - working body; 5 - secondary element of linear induction motor; 6 - inductor of linear induction motor roller; $\mathrm{a}-$ in the initial state; $b$ - in working condition.

Figure 3 shows the existing grain cleaning machine.

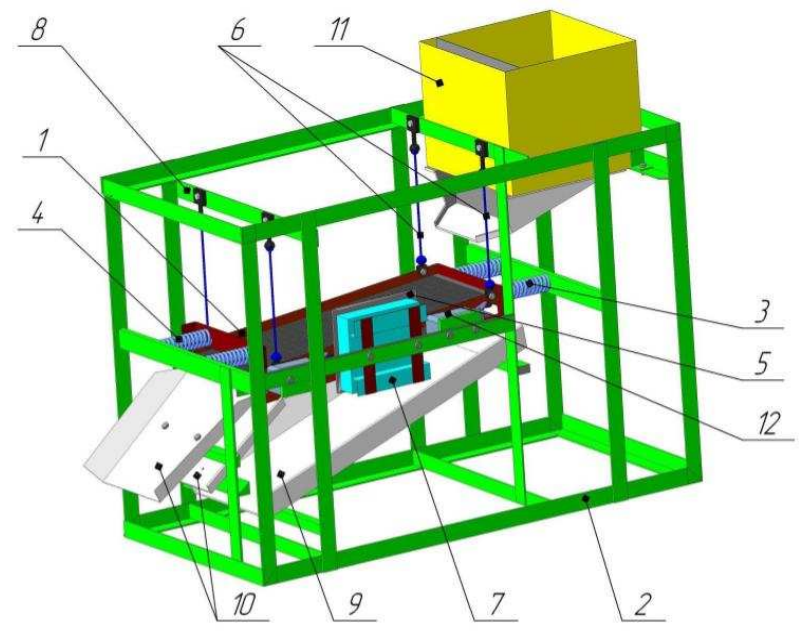

Fig. 3. - The grain-cleaning machine with a linear electric drive: 1 - grating mill; 2 - base; 3, 4 - elastic elements; 5 - secondary element of linear induction motor; 6 - elastic suspension brackets; 7 - inductor LAD; 8- frame-regulator; 9 - passing fraction; 10 - slipping fraction; 11 - bunker; 12 - thrust rollers.

However, when using the existing control system of an oscillating linear electric drive, there is significant overheating of the inductor windings of the linear induction motor when the latter is in the intermittent operation mode, which reduces its service life [3,7]. This is due to the fact that under the existing operating modes of the linear drive, most of the electrical energy consumed by the linear induction motor from the network is spent for braking and subsequent acceleration of the sieve mill in the cycle of oscillatory motion. In the work of the researchers [7, 9], to solve the above-mentioned problem, it is proposed using a pulsed operating mode of the linear electric drive of a grain cleaning machine, differing from the self-oscillating mode and the forced oscillation mode. In it, the linear induction motor is connected to the power source at the moment of stopping the motion of the sieve mill in one direction. Herewith, there is a need to conduct studies on the effect of the duration of the connected state of the linear induction motor on the performance indicators of the grain cleaning machine (Fig. 4-5).

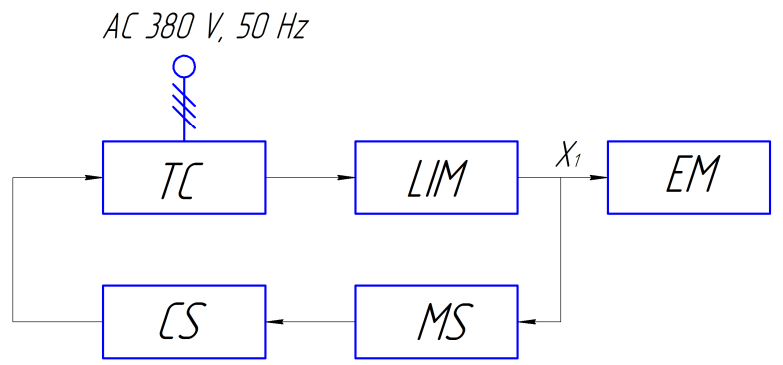

Fig. 4. - A functional diagram of the self-oscillating mode of the linear electric drive of a sieve mill: TC - thyristor commutator; LIM - linear induction motor; EM - elastic matarial; CS - control system; MS - optical motion sensor.

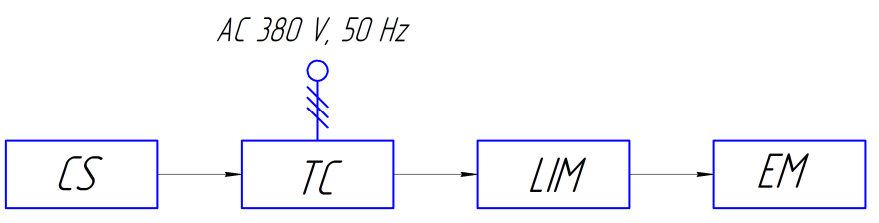

Fig. 5. - A functional diagram of the forced oscillation mode of the linear electric drive of the sieve mill: TC - thyristor commutator; LIM - linear induction motor; EM - elastic matarial; CS - control system.

\section{MiCROPROCESSOR CONTROL SYSTEM OF LINEAR ElECTRIC Drive Of SIEVE MiLl Of GRain CleANing MACHINE}

It is possible to realize the pulsed operating mode of the linear electric drive of the sieve mill when using a microprocessor control system (Fig. 6). In this case, the ratio between the frequency of the periodic action of traction force $\omega_{F}$ and natural frequency of the oscillatory system $\omega_{S}$ increases, which in the end allows one to reduce the necessary electric motor power for excitation and maintenance of the oscillating process of the sieve mill $[4,5]$.

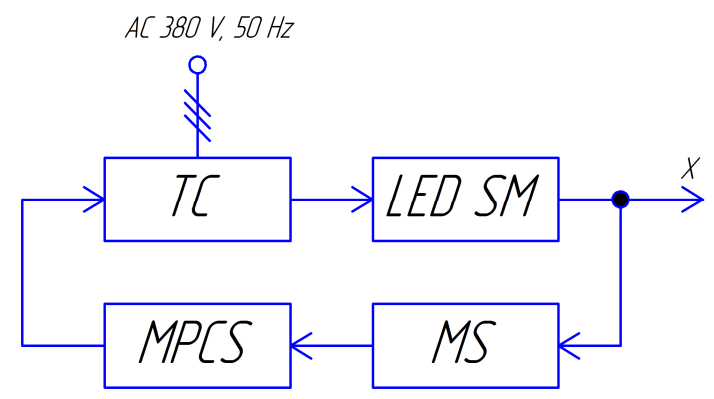

Fig. 6. - A functional diagram of the pulsed operating mode of the linear electric drive of the sieve mill: TC - thyristor commutator; LED SM - linear electric drive of the sieve mill; MPCS - microprocessor control system; MS optical motion sensor; $\mathrm{X}$ - displacement of the sieve mill. 
The microprocessor system is used to regulate and maintain the maximum acceleration of the sieve mill, a change in the value of which may lead to a stopping of the movement of the grain mixture, or to its reverse movement along the surface of the sieve [10].

The process of operation of the microprocessor control system is as follows. The optical movement sensor locks the linear movement of the sieve mill in the longitudinal direction and transmits the current information about the position of the sieve mill to the microprocessor control system. The latter in the process of work determines the moment when the sieve mill stops after one oscillation period $T$ and connects a linear induction motor to a power source with duration $t_{d}$. The microprocessor control system also determines and, if necessary, regulates the maximum value of sieve mill acceleration $a_{s . m .}$.

\section{INVESTIGATING THE IMPULSE MODE OF THE LINEAR} ELECTRIC DrIVE Operation OF THE SIEVE MILl OF A Grain CleANING MACHINE

To determine the value of the maximum acceleration of sieve mill $a_{\max }$, during which the maximum productivity of grain cleaning machine $Q_{\max }$ is reached, theoretical studies were carried out in the environment of visual object-oriented modeling MATLAB / SIMULINK. In the process of research, initial productivity $Q$ is assumed to be 0.5 ton / h (similar to the seed cleaner MVR-2 (SU-0.1)). In this case, it is assumed that a grain material with a mass of $6 \mathrm{~kg}$ is located on the surface of the sieve.

Fig. 2 shows the dependence obtained, showing the necessary power of linear induction motor $P_{1}$ for the process of grain separation, during which maximum productivity $Q_{\max }$ is achieved. As Fig. 7 shows, maximum productivity $Q_{\max }$ is achieved at capacity of $0.6 \mathrm{~kW}$ of a linear induction motor.

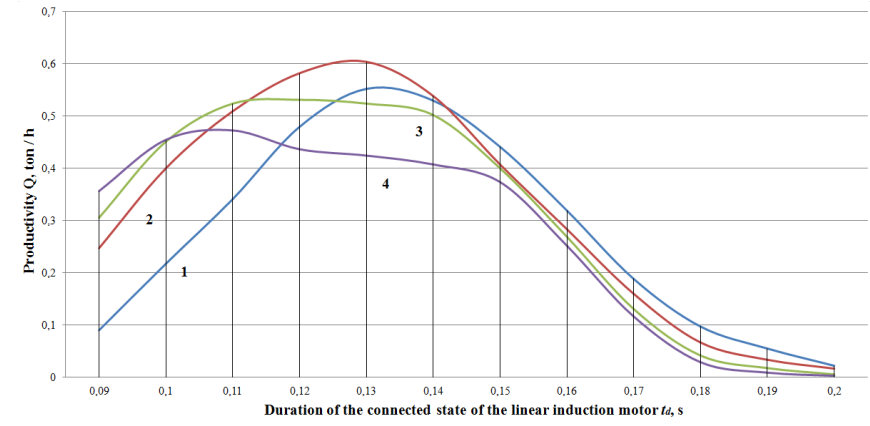

Fig. 7. - Dependence of productivity $Q$ on the duration of the connected state of a linear induction motor at capacity $P_{l}$ of the latter: $1-0.5 \mathrm{~kW} ; 2$ $0.6 \mathrm{~kW} ; 3-0.7 \mathrm{~kW}$ and $4-0.8 \mathrm{~kW}$.

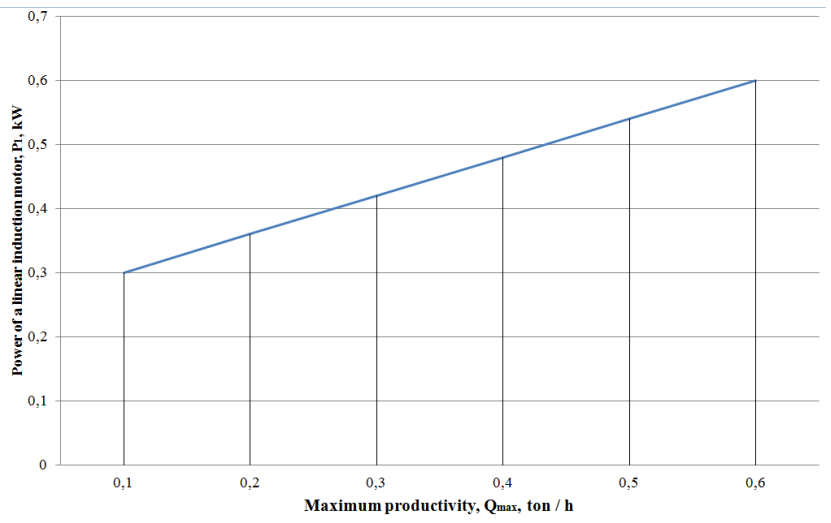

Fig. 8. - Dependence of power $P_{l}$ of linear induction motor on maximum productivity $Q_{\max }$

Fig. 8 shows the dependence showing the value of power $P_{1}$ of the linear induction motor, at which the maximum productivity $Q_{\max }$ is achieved.

Fig. 9 shows the dependence of productivity $Q$ on the value of the maximum acceleration of the sieve mill.

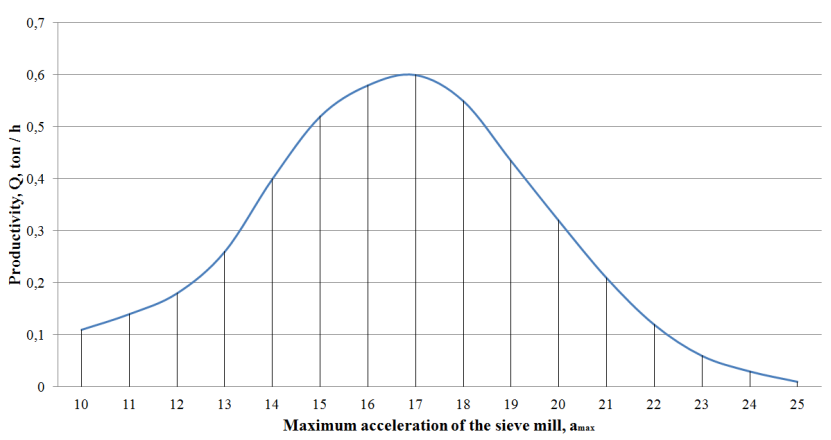

Fig. 9. - The dependence of productivity $Q$ on the value of maximum acceleration of sieve mill $a_{\max }$.

Proceeding from the presented dependence, maximum productivity $Q_{\max }=0.6$ ton / h is reached under the maximum acceleration of the sieve mill equal to $a_{\max }=17 \mathrm{~m} / \mathrm{s}^{2}$.

\section{ANALYSIS OF EXPERIMENTAL RESEARCH RESUltS IN PRODUCTION CONDITIONS}

Experimental work was carried out to determine the quality of grain separation on an existing grain cleaning machine using an electric drive based on a linear induction motor. For this purpose, the seed cleaner MVR-2 (SU-0.1) has been modernized.

An experimental study of the efficiency of the separation process was carried out on a multicomponent mixture, consisting of completely wheat seeds and various weed impurities. The studies were carried out according to the following method. The grain material was poured into the bunker installations. There was fixed supply of grain from the hopper to a grain sieve $q$. The angle of inclination of a grain sieve was $\alpha$; the amplitude of oscillation of a grain sieve was in longitudinal $A_{1}$ and transverse $A_{2}$ directions; oscillation 
frequency $w$ of a grain sieve with changing one of the factors with constancy of the other. The authors were running the installation, and after a stable operating regime was established, the grain fraction was sampled within 30 seconds to determine the separation efficiency.

During the production tests, the authors determined the dependence of the efficiency of linear electric drive $\eta$ of the sieve mill on the duration of the state of the linear induction motor, connected to the power source at various capacities of the linear induction motor. It was obtained in the "Ilish-Agro" LLC of the Ilishevsky District of the Republic of Bashkortostan (Fig. 10). Analysis of this dependence shows that maximum $\eta=42 \%$ is reached when $P_{1}=0.6 \mathrm{~kW}$.

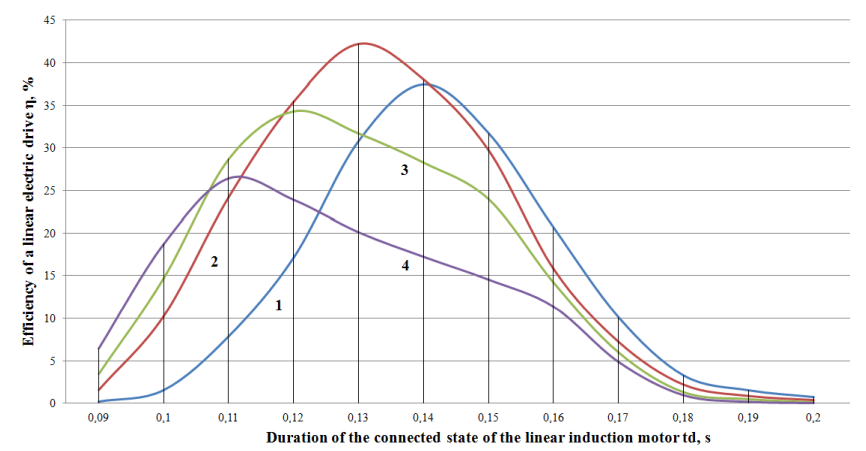

Fig. 10. - Dependence of the efficiency of linear electric drive $\eta$ of a grate mill on the duration of the connected state of a linear induction motor at capacity $P_{l}$ of the latter: $1-\mathrm{kW} ; 2-\mathrm{kW} ; 3-\mathrm{kW}$ and $4-\mathrm{kW}$.

Based on the results of the production tests, the dependences of grain losses $L$, grain siftability $S$ and the completeness of grain separation $C$ on productivity at various kinematic operating modes of a sieve mill were obtained, which together allow for a full evaluation of the efficiency of grain material purification from weed impurities (Fig. 11-12).

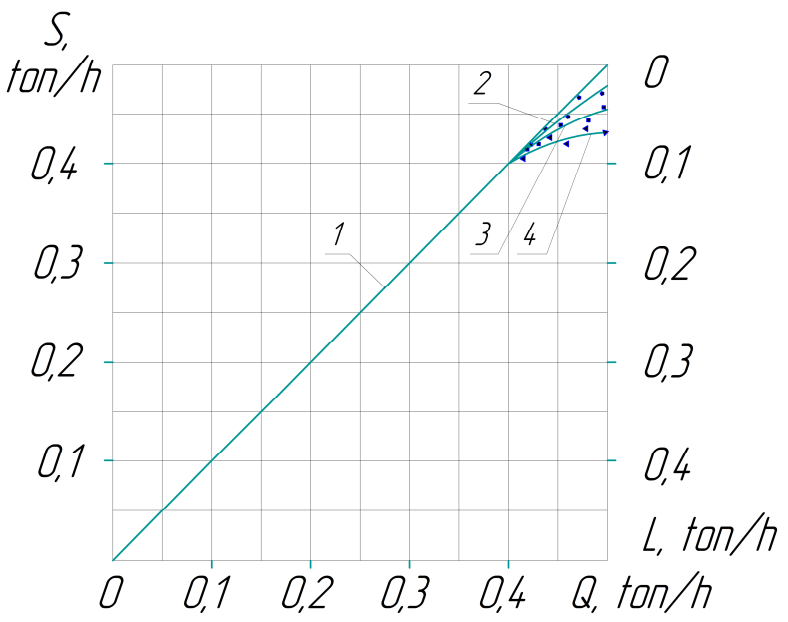

Fig. 11. - Dependences of the sifting and loss of grain on productivity under different kinematic modees of operation of grain sieve: 1 - maximum sifting; 2 - mode $A \cdot f=43.5 \mathrm{~mm} \cdot \mathrm{Hz} ; 3$ - mode $A \cdot f=48 \mathrm{~mm} \bullet \mathrm{Hz} ; 4$ - mode $A \cdot f=$ $52.5 \mathrm{~mm} \cdot \mathrm{Hz} ; A$ - amplitude of oscillation in the longitudinal direction; $f$ oscillation frequency in the longitudinal direction.

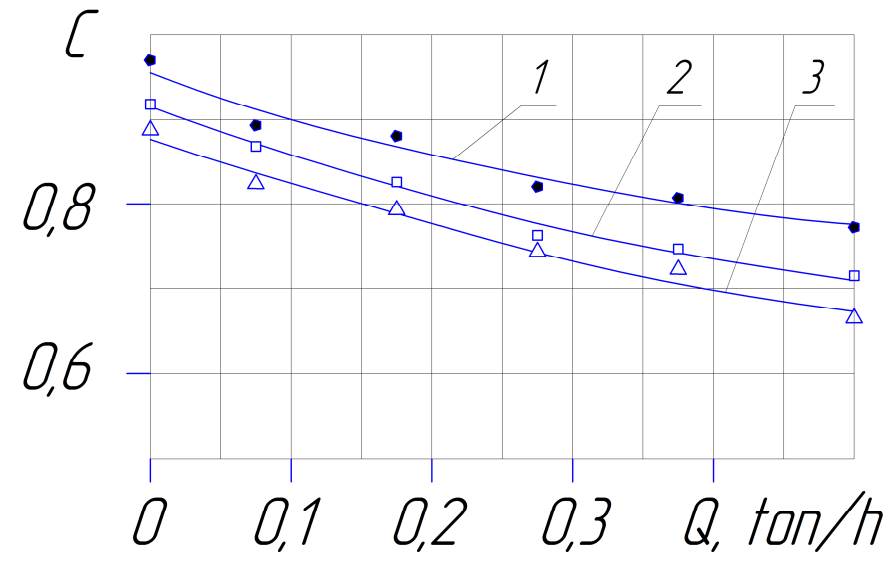

a

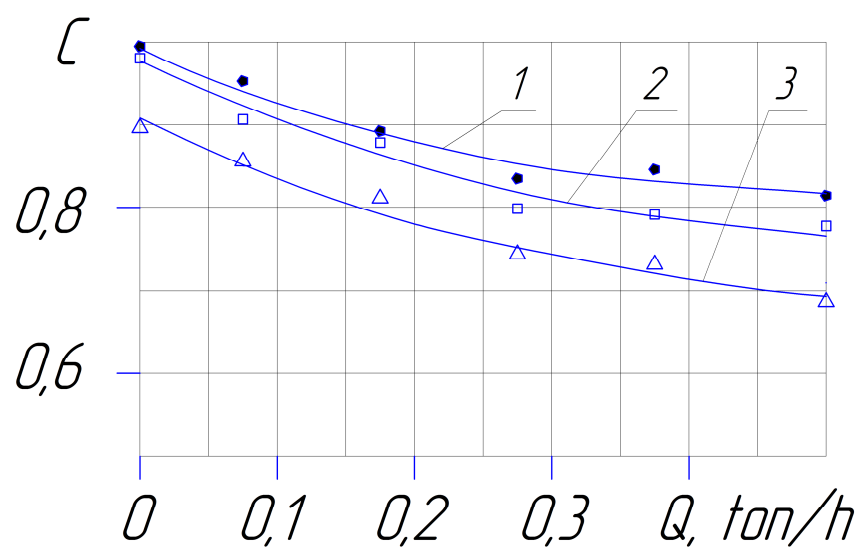

b

Fig. 12. - The dependence of the completeness of the separation of grain material on productivity under various kinematic regimes of the work of the cleaning sieve (a) and the sorting sieve (b): 1 - mode $A \cdot f=43.5 \mathrm{~mm} \bullet \mathrm{Hz} ; 2$ mode $A \cdot f=48 \mathrm{~mm} \cdot \mathrm{Hz} ; 3-\operatorname{mode} A \cdot f=52.5 \mathrm{~mm} \cdot \mathrm{Hz}$.

The pulse mode of operation of the linear electric drive, unlike other work modes, is the most energy efficient (Fig. 13).

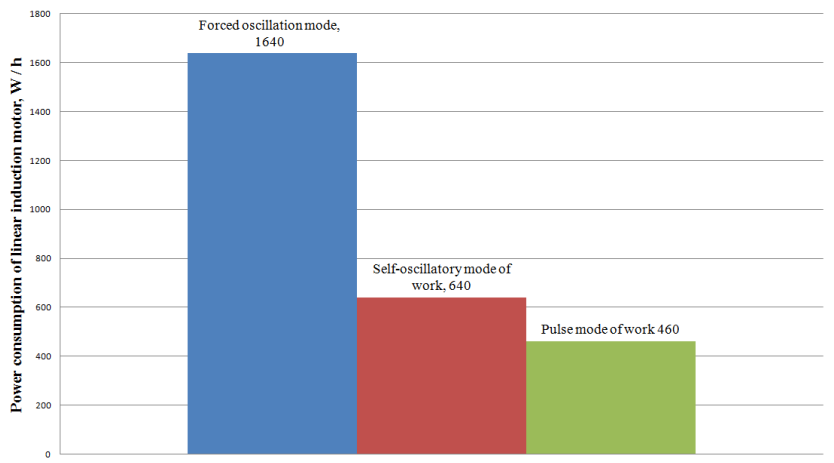

Fig. 13. - The value of the power consumption of a linear electric drive in different modes of operation.

Figure 14 shows the trajectory of a sieve mill movement. 


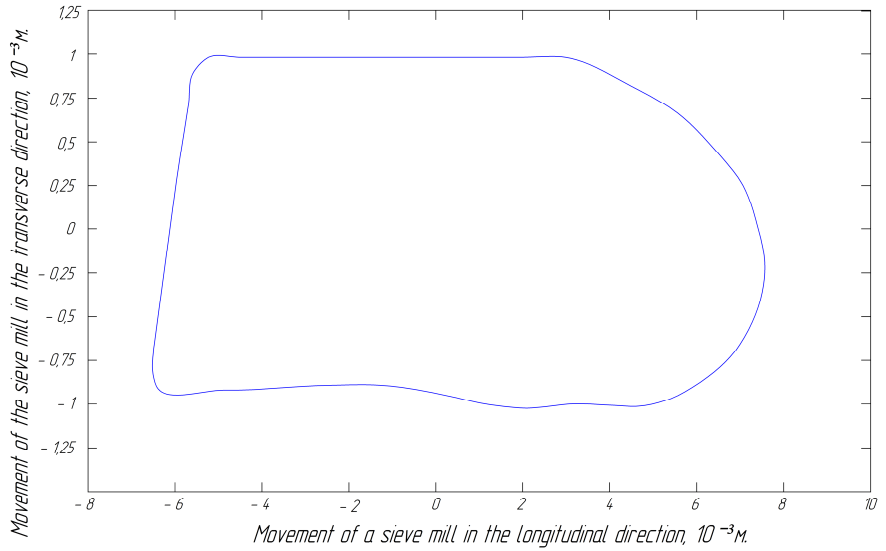

Fig. 14. - Trajectory of the motion of a sieve mill.

Figure 15 shows the dependence of inductor current $I_{l}$ on voltage $U_{l}$ applied to the motor for different resistance forces $F_{c 1}<F_{c 2}<F_{c 3}<F_{c 4}$.

These dependences are sometimes called U-shaped characteristics of a linear inductor motor. As can be seen from the graph, with each load of the motor there is a supply voltage $U_{l}$ by which consumption of current $I_{l}$ is minimal. The current decreases due to a decrease of the reactive component in it. Thereby the energy loss in the engine decreases, thus increasing its efficiency and power factor.

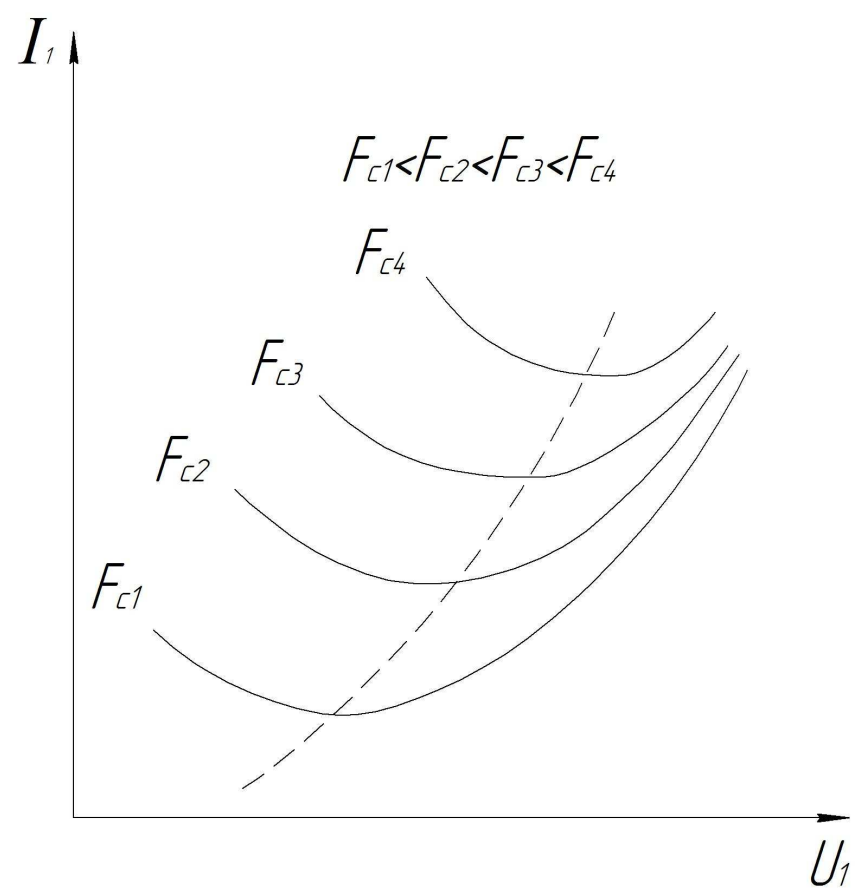

Fig. 15. - The dependence of inductor current $I_{l}$ on voltage $U_{l}$ applied to the motor for different resistance forces $F_{c 1}<F_{c 2}<F_{c 3}<F_{c 4}$

\section{CONCLUSION}

Thus, the conducted studies have shown that the use of a linear electric drive in the MVR-2 (SU-0.1) operating in the pulsed mode allows increasing productivity $Q$ by $20 \%$. It is determined that the use of a linear electric drive allows the reduction of the consumed power and elimination of superheating the inductor windings.

[1] R.S. Aipov, "Fundamentals of construction and theory of linear electric drives with elastic energy stores", Ufa: Publishing House of Bashkir State Agrarian University, 2006, 295 p.

[2] R.S. Aipov, A.V. Linenko, V.G. Bainazarov, "Methodological basis for the development of an oscillatory linear electric drive, as a mechatronic system". Mechanization and electrification of agriculture I, pp. 20-22, 2016 .

[3] V.A. Butorin, I.V. Novik, "Increase of operational reliability of induction motors", Actual problems of energy AIK VI International scientific and practical conference. - Chelyabinsk: Publishing House of South Ural State Agrarian University, pp. 209-210, 2015.

[4] V.I. Gostev, "Fuzzy regulators in automatic control systems". Kiev: Publishing House of Radiomator, 2008, 978 p.

[5] A.V. Linenko, M.F. Tuktarov, S.V. Akchurin, "Analysis of the operation drive of a grain sieve of an experimental grain cleaning plant using a linear electric motor", Journal of the Ulyanovsk State Agricultural Academy II(18), pp. 97-101, 2012.

[6] M.F. Tuktarov, V.G. Bainazarov, "Control system for linear electric drive of grain cleaning machine with fuzzy controller". Science of young people - innovative development of the agro-industrial complex, Materials of the International Youth Scientific and Practical Conference, Ufa: Publishing House of Bashkir State Agrarian University, 2016, pp. 123-126.

[7] M.F. Tuktarov, Sh.F. Siraev, V.G. Bainazarov, "Pulse operating mode work of the linear electric drive of a grain cleaning machine", Journal of the Bashkir State Agrarian University I(41), Ufa: Publishing House of Bashkir State Agrarian University, 2017, pp. 69-73.

[8] R.B. Yarullin, R.R. Safin, "To the question of design of a self-regulating inertia vibrator of an asynchronous electric drive", Electrical and information complexes and systems III(10). - Ufa: Publishing house of UGUES, 2014, P. 30-37.

[9] R.B. Yarullin, A.R. Mulyukov, "The role of vibration in the intensification of technological processes", Collection of scientific works of the international correspondence scientific-practical conference, Ufa: Publishing House of Ufa State University of Economics and Service, 2015, pp. 65-67.

[10] M.F. Tuktarov, V.G. Bainazarov, "Control system of linear electric drive of grain cleaning machine with fuzzy controller",. Materials of the International Youth Scientific and Practical Conference (II), Ufa: Publishing House of Bashkir State Agrarian University, 2016, pp. 123126. 